\title{
Measures of emotion: A review
}

\author{
Iris B. Mauss and \\ University of Denver, Denver, CO, USA \\ Michael D. Robinson \\ North Dakota State University, Fargo, ND, USA
}

\section{Abstract}

A consensual, componential model of emotions conceptualises them as experiential, physiological, and behavioural responses to personally meaningful stimuli. The present review examines this model in terms of whether different types of emotion-evocative stimuli are associated with discrete and invariant patterns of responding in each response system, how such responses are structured, and if such responses converge across different response systems. Across response systems, the bulk of the available evidence favours the idea that measures of emotional responding reflect dimensions rather than discrete states. In addition, experiential, physiological, and behavioural response systems are associated with unique sources of variance, which in turn limits the magnitude of convergence across measures. Accordingly, the authors suggest that there is no "gold standard" measure of emotional responding. Rather, experiential, physiological, and behavioural measures are all relevant to understanding emotion and cannot be assumed to be interchangeable.

\section{Keywords}

Emotion; Measurement; Self-report; Autonomic nervous system; Startle modulation; Central nervous system; Behaviour; Specificity

From an intuitive layperson perspective, it should be easy to determine whether someone is experiencing a particular emotion. However, scientific evidence suggests that measuring a person's emotional state is one of the most vexing problems in affective science. To organise our review of research relevant to this question, we take as our starting point a consensual, componential model of emotion (see Figure 1). In this model, an emotional response begins with appraisal of the personal significance of an event (Lazarus, 1991;Scherer, 1984;Smith \& Ellsworth, 1985), which in turn gives rise to an emotional response involving subjective experience, physiology, and behaviour (Frijda, 1988;Gross, 2007;Lang, 1988;Larsen \& Prizmic-Larsen, 2006) The present review examines whether emotion-evocative stimuli are associated with discrete patterns of responding in each system, how such responses seem to be structured, and if such responses converge (i.e., are co-ordinated or correlated) with one another.

Because the literatures that are relevant to the questions examined here are extensive, the present review must be selective. In our review, we concentrate on studies involving nonclinical human adult samples rather than children, animals, or clinical populations. We focus on the response components depicted in Figure 1 rather than on cognitive antecedents and correlates of emotion. To further constrain the scope of our review, we focus on emotional

Correspondence should be addressed to: Iris B. Mauss, Department of Psychology, University of Denver, Denver, CO 80208, USA. Email: imauss@psy.du.edu. 
states rather than emotion-related traits such as extraversion and neuroticism (see Matthews \& Gilliland, 1999; Robinson \& Neighbors, 2006;Rusting, 1998, for relevant reviews). Finally, we focus our review on the most commonly used measures for each response system.

Throughout our review, we examine findings from both dimensional and discrete perspectives. According to the dimensional perspective, there are a few fundamental dimensions that organise emotional responses. The most commonly assumed dimensions are valence, arousal (sometimes referred to as activation), and approach-avoidance (Davidson, 1999; Lang, Bradley, \& Cuthbert, 1997; Russell \& Barrett, 1999; Schneirla, 1959; Watson, Wiese, Vaidya, $\&$ Tellegen, 1999). The valence dimension contrasts states of pleasure (e.g., happy) with states of displeasure (e.g., sad), and the arousal dimension contrasts states of low arousal (e.g., quiet) with states of high arousal (e.g., surprised). Approach motivation is characterised by tendencies to approach stimuli (e.g., as would likely be facilitated by excitement), whereas avoidance motivation is characterised by tendencies to avoid stimuli (e.g., as would likely be facilitated by anxiety).

Researchers disagree to some extent about which dimensional scheme should be used and how different dimensions relate to each other. For example, some theorists state that positive and negative emotions are inversely related (Russell, 1980), but others favour the view that positive and negative emotions are relatively independent of each other (Larsen, McGraw, \& Cacioppo, 2001; Tellegen, Watson, \& Clark, 1999). In addition, some argue that approach and avoidance are more or less synonymous with positive and negative emotional states, respectively (Watson et al., 1999). However, as we outline below, some emotional states such as anger pose problems for this view, in that they suggest a dissociation of valence and approach-avoidance (HarmonJones \& Allen, 1998). More generally, our review will make it clear that different measures of emotion are particularly sensitive to different dimensions; thus, for different measures different dimensional schemes are most appropriate. Although dimensional frameworks disagree in some of their specifics, they agree that emotional states can be organised in terms of a limited number of underlying dimensions.

In contrast, the discrete emotions perspective contends that each emotion (e.g., anger, sadness, contempt) corresponds to a unique profile in experience, physiology, and behaviour (Ekman, 1999; Panksepp, 2007). It is possible to reconcile dimensional and discrete perspectives to some extent by proposing that each discrete emotion represents a combination of several dimensions (Haidt \& Keltner, 1999; Smith \& Ellsworth, 1985). For example, anger could be characterised by negative valence, high arousal, and approach motivation, whereas fear could be characterised by negative valence, high arousal, and avoidance motivation. Despite these considerations, dimensional and discrete perspectives differ in how they conceptualise and describe emotional states (Barrett, 2006b). For this reason, we contrast such perspectives in our review.

To guide the reader, Table 1 presents an overview of the measures reviewed for each response system depicted in the consensual model of Figure 1. Table 1 also summarises our conclusions concerning the aspects of emotional state best captured by each measure. We begin by reviewing self-report measures of emotion.

\section{SELF-REPORT MEASURES OF EMOTION}

In our view, the validity of self-reports of emotion is too often seen as an all-or-none phenomenon. Here, we follow Robinson and Clore (2002), who concluded that the degree to which self-reports are valid varies by the type of self-report (see also Robinson \& Sedikides, in press). Specifically, self-reports of current emotional experiences are likely to be more valid than are self-reports of emotion made somewhat distant in time from the relevant experience (Robinson \& Clore, 2002). In a very interesting study, for example, Barrett, Robin, 
Pietromonaco, and Eyssell (1998) asked men and women to report on their emotional traits "in general" as well as on their emotional reactions to events in daily life. Sex differences in emotional traits were prominent and large, whereas sex differences in daily experience were quite meagre and inconsistent, suggesting that trait reports of emotion are more biased (in this case by gender stereotypes) than reports made directly after an event. Conceptually similar findings have been reported when asking individuals to estimate their past or likely future responses to emotional events (e.g., Mitchell, Thompson, Peterson, \& Cronk, 1997) On the basis of such evidence for bias, Robinson and Clore concluded that self-reports of one's current experience ("online") are likely to be more valid than self-reports concerning past, future, or trait-related experiences of emotion.

However, there are concerns that even "online" reports of emotion can be biased among certain groups of individuals. For example, it is thought that individuals high in social desirability may be less willing and/or capable of reporting negative emotional states (Paulhus \& Reid, 1991; Welte \& Russell, 1993). Although this suggestion has proven somewhat controversial (Shedler, Mayman, \& Manis, 1993; Taylor, Lerner, Sherman, Sage, \& McDowell, 2003), there are still concerns that individuals high in social desirability may give less valid reports of their emotions (Paulhus \& John, 1998). A second relevant individual-difference variable is alexithymia. It has been suggested that individuals high in alexithymia react to emotional stimuli, but are less capable of conceptualising their emotional experiences in a manner conducive to self-report (Lane, Ahern, Schwartz, \& Kaszniak, 1997). In sum, there are individual differences in awareness of and willingness to report on emotional states that potentially compromise even online reports of emotional experience.

Finally, one purpose of our review is to compare dimensional and discrete perspectives of emotional responding. In the domain of self-reported emotional states, it is quite clear that dimensions such as valence and arousal (Russell \& Barrett, 1999) or tendencies toward approach and avoidance (Watson et al., 1999) capture the lion's share of variance. Indeed, the dimensional nature of self-reported emotional responses is so substantial that it has been suggested that the dimensional correlates of self-reported emotion be examined first before there is any legitimate claim to emotion specificity (Watson, 2000).

\section{Summary}

Self-reports of emotion are likely to be more valid to the extent that they relate to currently experienced emotions. Even in this case, though, there are concerns that not all individuals are aware of and/or capable of reporting on their momentary emotional states. Finally, Table 1 follows from our review of this literature in suggesting that dimensional frameworks, relative to discrete ones, better capture this measure of emotion.

\section{AUTONOMIC MEASURES OF EMOTION}

The autonomic nervous system (ANS) is a general-purpose physiological system responsible for modulating peripheral functions (Öhman, Hamm, \& Hugdahl, 2000). This system consists of sympathetic and parasympathetic branches, which are generally associated with activation and relaxation, respectively. Because of the general-purpose nature of the ANS, its activity is not exclusively a function of emotional responding, but rather encompasses a wide variety of other functions related to digestion, homeostasis, effort, attention, and so forth (Berntson \& Cacioppo, 2000). This is an important point because it is often not clear whether activity in the ANS reflects emotional processes or, perhaps instead, other functions subserved by the ANS (Obrist, Webb, Sutterer, \& Howard, 1970; Stemmler, 2004).

The most commonly assessed indices of ANS activation are based on electrodermal (i.e., sweat gland) or cardiovascular (i.e., blood circulatory system) responses. Electrodermal responding 
is typically quantified in terms of skin conductance level (SCL) or short-duration skin conductance responses (SCRs). The most commonly used cardiovascular measures include heart rate (HR), blood pressure (BP), total peripheral resistance (TPR), cardiac output (CO), pre-ejection period (PEP), and heart rate variability (HRV). Each of these measures varies in terms of whether it primarily reflects sympathetic activity, parasympathetic activity, or both. For example, SCL and PEP predominantly reflect sympathetic activity, HR and BP reflect a combination of sympathetic and parasympathetic activity, and HRV has been closely linked to parasympathetic activity (Cacioppo, Berntson, Larsen, Poehlmann, \& Ito, 2000).

James (1884) was among the first psychologists to suggest that different emotional states (e.g., sadness, anger, fear) involve specific patterns of ANS activation. James's speculations have been central to many important theories of emotion (Ellsworth, 1994; Lang, 1994), though Ellsworth cautions that it would be a mistake to equate James's theory with peripheral ANS responding considered alone. Nonetheless, much of the research inspired by James's theory of emotion has focused on ANS measures. One reason for the continued scientific interest in autonomic specificity is that people generally believe that their emotions involve discrete patterns of ANS activation (such as the presumed link between anxiety and increased heart rate: Scherer \& Wallbott, 1994). However, the validity of such beliefs is suspect because perceptions of ANS responses are generally not predictive of actual ANS responses (Mauss, Wilhelm, \& Gross, 2004; Pennebaker, 1982).

Furthermore, although some evidence for autonomic specificity has been reported (Christie \& Friedman, 2004; Ekman, Levenson, \& Friesen, 1983; Stemmler, Heldmann, Pauls, \& Scherer, 2001), a recent meta-analysis has characterised such effects as inconsistent (Cacioppo et al., 2000). In this meta-analysis, only a small set of the 37 ANS measures reviewed reliably differentiated discrete emotions and replicable findings were specific to particular comparisons (e.g., finger temperature decreases less in anger than in fear, but finger temperature does not differentiate other discrete emotions). Also, although there were mean differences in some ANS responses across emotions, results were highly inconsistent across studies. By contrast, different induction methods (e.g., directed facial expressions versus film clips) have much more reliable effects on ANS measures than different emotions, again highlighting the paucity of support for the autonomic specificity hypothesis (Cacioppo et al., 2000).

Given these considerations, it may be best to view ANS responding in terms of broader dimensions such as arousal (Cacioppo et al., 2000; Duffy, 1962; Malmo, 1959). In support of this point, Peter Lang and colleagues have shown, in a number of studies (e.g., Bradley \& Lang, 2000b; Lang, Greenwald, Bradley, \& Hamm, 1993), that SCL increases systematically and linearly according to the rated arousal of emotional stimuli (e.g., slides). Moreover, the same studies have found that relations between stimulus arousal and SCL activity are independent of stimulus valence, emotion induction method, and, indeed, which specific emotion is targeted by the induction. Such findings are consistent with theories contending that ANS activity indexes the arousal level of the emotional state rather than its discrete emotional basis (Arnold, 1960; Cannon, 1931; Duffy, 1962).

However, not all measures of ANS responding map onto a single dimension. According to the principle of "directional fractionation" (Lacey, 1967), different measures of ANS activity can operate independently or even in opposition to each other. For example, HR decreases can cooccur with increases in sympathetic activity as assessed by other ANS measures (Bradley \& Lang, 2000b; Lang et al., 1997; Libby, Lacey, \& Lacey, 1973). To explain such fractionation of the ANS system, at least one additional dimension must be taken into consideration (Cacioppo et al., 2000; Russell \& Barrett, 1999). Konorski, and later Lang (Konorski, 1967; Lang, Bradley, \& Cuthbert, 1990; Lang et al., 1997) proposed appetitive and aversive systems as the second important dimension of ANS responding; others have proposed a similar valence 
dimension (Cacioppo et al., 2000; Russell \& Barrett, 1999). For example, Cacioppo and colleagues' meta-analysis (2000) revealed that blood pressure, cardiac output, heart rate, and skin conductance response duration respond to emotional valence.

Although individual ANS measures appear responsive to dimensions rather than discrete emotional states, the joint consideration of multiple ANS measures may support a greater degree of autonomic specificity (Cacioppo et al., 2000; Stemmler, 2004). For example, Stemmler reports that anger and fear, despite being matched in terms of valence and arousal, could be differentiated by a combination of cardiovascular and respiratory measures. Similarly, Kreibig, Wilhelm, Roth, and Gross (2007) found that eleven ANS measures, jointly considered, differentiated responses to fear-inducing versus sadness-inducing film clips (matched on valence and arousal) with $85 \%$ accuracy. Thus, combinations of multiple ANS measures may yield better predictions of discrete emotional states. However, data of this type often capitalise on sample-specific findings and should be viewed as tentative in the absence of replications.

Recall, also, that ANS measures serve multiple masters including perceived and actual task demands, coping appraisals, and motor behaviour (Obrist et al., 1970; Stemmler, 2004). For this reason, it may be problematic to view any ANS pattern as a straightforward reflection of the emotional state of the individual. Such considerations are particularly problematic for views emphasising an invariant, unmediated influence of emotion on physiological responding (Panksepp, 1999; Tompkins, 1995). By contrast, if one views emotions as inextricably linked to task demands, coping, and motor behaviour (Ekman, 1999; Larsen, Berntson, Poehlmann, Ito, \& Cacioppo, in press; Levenson, 2003; Stemmler, 1989), then it is less of a concern that ANS activity responds to both emotional states and non-emotional factors.

\section{Summary}

The idea that discrete emotions have distinct autonomic signatures has not faired well in the literature. Instead, relevant studies often point to relationships among dimensions, particularly those of valence and arousal, and ANS responses. It is possible that considering patterns of multiple ANS measures will lead to autonomic specificity in the future, but more work is needed before coming to firm conclusions. Table 1 thus reinforces our central conclusion that ANS measures primarily respond to dimensional aspects of emotional states.

\section{STARTLE RESPONSE MAGNITUDE AS A MEASURE OF EMOTION}

Startle in response to a sudden, intense stimulus is a universal reflex that involves multiple motor actions, including tensing of the neck and back muscles and an eye blink (Landis \& Hunt, 1939). The startle response serves a protective function, guarding against potential bodily injury (particularly of the eye) and serving as a behavioural interrupt that is thought to facilitate vigilance in relation to a possible threat (Graham, 1979). In support of this hypothesis, the amygdala, which is a brain structure centrally involved in vigilance and threat detection (Whalen, 1998), plays a key role in modulating the startle response in threatening contexts (Davis, 1989; Koch \& Schnitzler, 1997). Because the startle response thus lies at the intersection of several response systems (ANS, CNS, and behaviour), we describe it in a separate section.

The most robust component of the behavioural cascade that constitutes the startle reflex is the eye blink. Therefore, the amplitude of the eye blink is usually used to index startle magnitude among human participants. Such procedures involve an electromyogram (EMG) measurement in which muscle activity is assessed from electrodes placed over the orbicularis oculi muscle, just beneath the lower eyelid. The most commonly used startle-eliciting stimulus is the socalled "startle probe", a brief (50 ms) burst of white noise within the 95-110 decibel range. 
Building to some extent on the work of Davis (1989), Lang (1995) made a strong case for the utility of startle amplitude as a measure of emotion. The logic here is that when the avoidance system is activated by a negative emotional state, then defensive responses (including the startle reflex) should be primed and thus increased relative to during neutral states. Conversely, higher levels of approach motivation likely inhibit tendencies toward a defensive orientation and should thus be associated with a lesser startle response magnitude relative to neutral states. Lang (1995) maps approach and avoidance onto positive and negative emotional states and thus hypothesises an inverse linear relationship between the valence of a person's emotional state and the startle response magnitude.

Lang's (1995) hypothesis has been strongly supported. Multiple studies have shown that when startle probes are delivered in the context of pictures and sounds that vary in valence, the magnitude of the startle response is larger in the context of unpleasant stimuli and smaller in the context of pleasant stimuli, both relative to neutral stimuli (Bradley, Cuthbert, \& Lang, 1993; Bradley \& Lang, 2000a; Vrana, Spence, \& Lang, 1988). Such effects have been linked to emotional valence rather than to discrete emotional states (Lang, 1995). Convergent support for the startle response as a measure of emotional valence comes from the clinical literature. Phobic individuals should exhibit greater negative emotion and thus larger startle responses to phobic stimuli, and this result has been reported (Cook \& Turpin, 1997). Conversely, individuals meeting criteria for psychopathy are thought to be deficient in threat processing. Consistent with this idea, such individuals, relative to non-psychopathic individuals, have been shown to exhibit smaller startle responses to threatening stimuli (Patrick, 1994).

Two important points qualify the general formulation that startle indexes emotional valence. First, it has been shown that startle magnitude is only sensitive to valence in the context of high-arousal stimuli (Cuthbert, Bradley, \& Lang, 1996; Lang, 1995). Second, the startle appears to be particularly useful for understanding reactivity to perceived stimuli such as emotional pictures relative to other induction methods such as conditioning or imagery (Mallan \& Lipp, 2007; Miller, Patrick, \& Levenston, 2002; Sabatinelli, Bradley, \& Lang, 2001). Within emotion-perception tasks, though, several potential confounds have been ruled out, including stimulus novelty, attentional factors, and sensory modality (Bradley, Cuthbert, \& Lang, 1990; Bradley et al., 1993; Hawk \& Cook, 1997; Lang et al., 1990Lang et al., 1997).

\section{Summary}

Together, the results summarised here suggest that the startle response is a marker of the valence dimension of emotional states. Specifically, as summarised in Table 1, the startle response is reliably larger in the context of high-arousal negative stimuli and reliably smaller in the context of high-arousal positive stimuli. At the same time, the measure does not appear to assess discrete emotional states.

\section{BRAIN STATES AS A MEASURE OF EMOTION}

Following early theorising by Cannon (1931) and Bard (1928), many investigators have proposed that the physiological correlates of discrete emotions are likely to be found in the brain rather than in peripheral physiological responses (Buck, 1999; Izard, 2007; Panksepp, 2007). Researchers have taken up this challenge using EEG and neuroimaging methods. Because these methods produce very different types of data, we review EEG and imaging results separately.

\section{Electroencephalography (EEG)}

Although the temporal resolution of EEG is excellent, its spatial resolution is limited (Dale \& Sereno, 1993). Thus, EEG measures typically contrast activation in fairly large regions of the 
brain, often anterior (i.e., front of brain) versus posterior (i.e., back of brain) in combination with the distinction between left-sided and right-sided hemispheric activation. The most common EEG measure of this type is alpha power (8-13 Hz band), which is thought to be inversely related to regional cortical activation (Allen, Urry, Hitt, \& Coan, 2004). In our review, we focus on what is termed "frontal asymmetry", which contrasts alpha power in the left frontal region with alpha power in the right frontal region, as this asymmetry-based measure has been particularly important to the emotion literature (Davidson, 1999).

Early studies of frontal asymmetry linked it to emotional valence. For example, Tomarken, Davidson, and Henriques (1990) found that greater left-sided activation at baseline predicted more intense experiences of positive than negative emotion, using a trait measure of emotional experience (although only among those individuals with stable EEG asymmetry profiles over time). Along similar lines, Davidson, Ekman, Saron, Senulis, and Friesen (1990) found that the induction of positive emotions by film clips led to greater left-sided frontal activation subsequent to the induction. These data suggest that frontal asymmetry assesses, or at least predisposes people to, pleasant emotional experiences (Davidson, 1999).

Subsequent studies, however, have provided convincing evidence that the frontal EEG asymmetry measure reflects the relative balance of approach versus avoidance motivation to a greater extent than it reflects emotional valence (Davidson, 1999). For example, Sutton and Davidson (1997) found that greater left-sided activation predicted dispositional tendencies toward approach, whereas greater right-sided asymmetry predicted dispositional tendencies toward avoidance. In contrast, the frontal asymmetry measure did not predict dispositional tendencies toward positive or negative emotions, suggesting an association of frontal asymmetry with approach-avoidance rather than with valence.

Other sources of data converge on a similar model of frontal asymmetry. Of particular importance are studies that link anger, an unpleasant but approach-related emotion, to greater left-hemispheric activation (Harmon-Jones \& Allen, 1998; Harmon-Jones, Lueck, Fearn, \& Harmon-Jones, 2006). Also, tendencies toward worry, thought to be approach-motivated in the sense of being linked to problem solving, have been linked to relatively greater left-frontal EEG activity (Heller, Schmidtke, Nitschke, Koven, \& Miller, 2002). Thus, the emerging consensus appears to be that frontal EEG asymmetry primarily reflects levels of approach motivation (left hemisphere) versus avoidance motivation (right hemisphere).

\section{Neuroimaging studies}

Neuroimaging studies, using fMRI (functional magnetic resonance imaging) or PET (positron emission tomography) technologies, can locate activation in far more specific brain regions than EEG. For this reason, it has been proposed that neuroimaging methods may be better suited than EEG to reveal emotion specificity in the brain (Panksepp, 1998). fMRI measures the uptake of oxygen in the blood (the "blood oxygenation level dependent" or BOLD signal; Detre \& Floyd, 2000). PET assesses metabolic activity in the brain through the injection of a radioactive isotope the concentrations of which can be measured by a positron-emitting radioisotope (Volkow, Rosen, \& Farde, 1997). In both technologies, the assumption is that a greater signal reflects greater blood flow to a particular brain region, which in turn is thought to reflect activation of that region. For the sake of convenience, then, we refer to both sources of data in terms of the "activation" of the relevant brain region.

At the outset, it must be mentioned that any complex reaction such as an emotional state is likely to involve circuits rather than any brain region considered in isolation (Kagan, 2007; LeDoux, 2000; Storbeck, Robinson, \& McCourt, 2006). However, particular brain regions may play a relatively greater or lesser role within larger circuits; thus localisation studies are meaningful in identifying the key regions involved. Our review here follows from two meta- 
analyses examining whether fear, disgust, sadness, and happiness can be linked to activation in particular brain regions (Murphy, Nimmo-Smith, \& Lawrence, 2003; Phan, Wager, Taylor, \& Liberzon, 2002). The majority of the reviewed studies were included in both meta-analyses, but the two meta-analyses differed somewhat in their analytic approach and, indeed, in their conclusions, as documented next.

The strongest apparent relation in both meta-analyses is between fear stimuli and amygdala activation (Murphy et al., 2003; Phan et al., 2002). However, there are reasons to resist the idea that amygdala activation is a straightforward reflection of fear. The amygdala is particularly responsive to fearful images relative to other fear-induction methods, and may thus be more closely tied to emotional perception than emotional experience (Wager et al., 2008). Moreover, the amygdala primarily responds to uncertainty and ambiguity, even relative to expected and unambiguous fearful stimuli (LeDoux, 1996; Pessoa, Padmala, \& Ungerleider, 2005; Whalen, 1998). Additionally, other data have linked amygdala activation to negative emotions more generally (Cahill et al., 1996) and even to reward processing and positive emotional states (Canli, 2004; Murray, 2007). Finally, it has been shown that individuals with bilateral damage to the amygdala can experience negative emotions, including fear (Anderson \& Phelps, 2001 Anderson \& Phelps, 2002). The preponderance of evidence thus suggests that the amygdala primarily responds to unexpected inputs of motivational significance rather than the experience of fear or processing of fear-related stimuli per se (Barrett, 2006b; Berridge, 1999; Holland \& Gallagher, 1999).

Both meta-analyses agree that disgust stimuli tend to be associated with insula activation. However, the meta-analysis of Phan et al. (2002) found that a wide variety of negative emotion inductions activated the insula as well. Thus, the idea that there is a specific link between insula activation and disgust appears problematic. Furthermore, the insula supports many psychological functions, including processing of taste information, implicit learning, procedural memory, and motor performance (e.g., Frank, O’Reilly, \& Curran, 2006; Keele, Ivry, Mayr, Hazeltine, \& Heuer, 2003; Kiefer \& Orr, 1992). For these reasons, it is difficult to endorse the simple view that insula activation can be equated with disgust.

Considering sadness, Phan et al. (2002) reported that $60 \%$ of the studies they reviewed found activation in the medial prefrontal cortex (mPFC), but Murphy et al. (2003) reported the strongest localisation pattern in the supracallosal anterior cingulate cortex (ACC; with about $50 \%$ of studies manipulating sadness showing this effect). This may not be an important discrepancy because the supracallosal ACC is well connected to areas of the mPFC, and thus an ACC-mPFC circuit may be involved in sadness. However, Barrett (2006a) raised an important concern about such studies, namely that they typically relied on induction methods involving high cognitive demand such as recalling a past event that caused sadness. This is an important potential confound because Phan et al. reported that cognitively demanding emotion inductions activate rostral portions of the ACC to a greater extent than passive emotional processing tasks do. This presents a concern for claiming a 1-to-1 correspondence of sadness to activation of an ACC-mPFC circuit.

The neural correlates of anger and happiness have been even less robust than those discussed above (Murphy et al., 2003; Phan et al., 2002). Furthermore, for the correlates reported, there are potential confounds such as those pertaining to the induction method used (Barrett,

2006a; Wager et al., 2008). In addition, there are concerns that some of the studies reviewed in the two meta-analyses used methods that have limited spatiotemporal resolution. Thus, although there has been some progress in understanding the neural correlates of fear, disgust, and potentially sadness, the discrete-emotions perspective has yet to produce strong, replicable findings. 
At the same time, meta-analyses provide support for a dimensional perspective on emotion and brain activity. Consistent with the EEG data reported above, approach-related emotional states appear to be left-lateralised in the brain (Murphy et al., 2003; Wager, Phan, Liberzon, \& Taylor, 2003). In addition to these lateralised patterns, Wager et al. (2003) found systematic relations between approach-motivated states and anterior and rostral portions of the medial prefrontal cortex (PFC) as well as the nucleus accumbens. Wager et al. (2003) also found systematic relations between avoidance-motivated states and the amygdala (especially its lateral and basolateral nuclei) and the ACC. Thus, there is increasing evidence that emotional states related to approach and avoidance involve localisable brain circuits (Barrett \& Wager, 2006; Wager et al., 2008).

\section{Summary}

EEG and neuroimaging studies converge in concluding that relative left-hemisphere activation is reflective of approach-related states, whereas relative right-hemisphere activation is reflective of avoidance-related states. Specific brain regions, too, appear to be linked to states of approach and avoidance, as reviewed in the section on neuroimaging studies. Table 1 thus concludes that CNS measures appear to be sensitive to the dimensions of approach and avoidance. That said, because emotional states are complex and likely to involve circuits, neuroimaging methods that examine interrelated activity among multiple brain regions may hold more promise for understanding whether and how emotional specificity is instantiated in the brain.

\section{BEHAVIOUR AS A MEASURE OF EMOTION}

Darwin (1965) suggested that emotions serve an evolved communicative function and thus should prime behaviours that reveal one's emotional state to others (see Ekman, 1992, for a related view). Another set of theories links emotional states to action dispositions, such as the primed tendency toward flight in the case of fear (Frijda, 1986; Lang et al., 1997). According to these theories, it should be possible to infer a person's emotional state from vocal characteristics, facial displays, and whole-body behaviours. We next review progress in this area of research. Because the term "expression" implies that emotions naturally trigger a given behaviour, we refer to "behaviour" or "movement" rather than "expression".

\section{Vocal characteristics}

People often report that they infer the emotional states of others from vocal characteristics (Planalp, 1998). Scientific studies have examined this intuition most commonly by decomposing the acoustic waveform of speech and then assessing whether such acoustic properties are associated with the emotional state of the speaker (Juslin \& Scherer, 2005). In our review, we concentrate on the most common measures, namely voice amplitude (i.e., loudness) and pitch (also known as fundamental frequency or $\mathrm{F}_{0}$ ). Although advances in the digital analysis of sound waveforms have made it increasingly feasible to measure other vocal characteristics such as minute changes of vocal-fold vibration (see Bachorowski \& Owren, 1995; Protopapas \& Lieberman, 1997, for reviews), work of this complex type is just beginning and much remains to be learned (Juslin \& Scherer, 2005).

The most consistent association reported in the literature is between arousal and vocal pitch, such that higher levels of arousal have been linked to higher-pitched vocal samples (Bachorowski, 1999; Kappas, Hess, \& Scherer, 1991; Pittam, Gallois, \& Callan, 1990). For example, Scherer, Banse, Wallbott, and Goldbeck (1991) examined the acoustic features of emotional nonsense sentences spoken by actors. When the actors were depicting high-arousal emotions such as fear, joy, and anger, pitch was higher than when they were depicting lowerarousal emotions such as sadness. Similar findings have been reported in studies of vocal 
characteristics following success or failure feedback and in the context of naturalistic studies of emotion and vocal responses (Bachorowski \& Owren, 1995).

Based on results of this type, Bachorowski and Owen (1995) suggested that vocal pitch can be used to assess the level of emotional arousal currently experienced by the individual. On the other hand, it has been more difficult to find vocal characteristics that are sensitive to valence (Bachorowski, 1999; Leinonen, Hiltunen, Linnankoski, \& Laakso, 1997; Protopapas \& Lieberman, 1997). For example, anger and joy are similar in emotional arousal, but different in valence, yet both emotions have been linked to comparable vocal pitch and vocal amplitude (Johnstone \& Scherer, 2000).

In the most comprehensive study that we know of, Banse and Scherer (1996) examined relations between 14 induced emotions and 29 acoustic variables. The authors found that a combination of ten acoustic properties differentiated discrete emotions to a greater extent than could be attributed to valence and arousal alone. For example, elation was characterised by medium low frequency (LF) energy and an increase of pitch over time, whereas anger was characterised by low LF energy and a decrease of pitch over time. However, these links were complex and multivariate in nature, involving post hoc comparisons that were novel to the literature and in some cases perhaps not theoretically motivated. Thus, replications are crucial to having greater confidence in the findings reported in this study.

\section{Facial behaviour}

Darwin (1965) reasoned that facial displays are closely tied to the likely behaviour of the organism (e.g., biting in the case of anger, which would result in exposed teeth). Darwin further contended that such emotion-behaviour links reflect biologically evolved mechanisms, in that they subserve survival-related actions and communication functions. Ekman built on Darwin's analysis and showed that prototypic facial behaviours of at least six "basic" emotions (anger, fear, disgust, happiness, sadness, and surprise) could be recognised cross-culturally (Ekman \& Friesen, 1971; Ekman, Sorenson, \& Friesen, 1969; Fridlund, Ekman, \& Oster, 1987; Izard, 1971). It is a different question - and one more pertinent to our review- to consider whether people spontaneously display such prototypic facial behaviours when in a particular emotional state.

Observer ratings-To examine the latter question, we review emotion-induction studies that have sought to link an induced emotional state to facial behaviours displayed during or immediately after the induction. Many of the relevant studies have quantified facial behaviour using componential coding. In most componential coding systems, trained coders detect facial muscle movements - or "facial actions" - using reliable scoring protocols (see Cohn \& Ekman, 2005; Ekman \& Friesen, 1978, for a comprehensive review). The most widely used componential coding system is the Facial Action Coding System (FACS; Ekman \& Friesen, 1978; Ekman, Friesen, \& Hager, 2002). The FACS is an anatomically based, comprehensive measurement system that assesses 44 different muscle movements (e.g., raising of the brows, tightening of the lips). As such, it measures all possible combinations of movements that are observable in the face rather than just movements that have been theoretically postulated. Other coding schemes seek to streamline the coding efforts by focusing on facial muscle contractions that are thought to have emotional significance (e.g., Izard, 1971; Kring \& Sloan, 2007).

Facial behaviours appear to reliably indicate the valence of a person's emotional state (Russell, 1994). For example, Duchenne ("non-social") smiles—involving wrinkling of the muscles around the eyes - have often been linked to experiences of positive emotion (Ekman, Davidson, \& Friesen, 1990; Frank, Ekman, \& Friesen, 1993; Hess, Banse, \& Kappas, 1995; Keltner \& Bonanno, 1997). By contrast, negative emotion inductions are often associated with a visible facial behaviour in which the eyebrows are lowered and brought closer together (Kring \& 
Sloan, 2007). In a recent study using a more molar facial action coding system, Mauss, Levenson, McCarter, Wilhelm, and Gross (2005) found strikingly large correlations between valence and the person's facial behaviours, $r \mathrm{~s}>.80$.

The case for the emotion specificity of facial behaviour has been more problematic and, indeed, very few studies of this type have been reported. In one such study, Rosenberg and Ekman (1994) exposed participants to disgust- and fear-inducing film clips. Following each film clip, participants rated their experience of eight discrete emotions. Subsequently, videotaped facial behaviour was scored in terms of the same eight discrete emotions. The researchers then determined whether discrete experiences and facial behaviours co-occurred beyond chance level. This was the case, but such relationships were also weak and not very robust in nature (see Bonanno \& Keltner, 2004, for additional results of this type).

Other results, though, present challenges for the entire enterprise of treating facial behaviours as a reflection of the person's emotional state, regardless of. whether a dimensional or discrete perspective is adopted. For example, Schneider and Josephs (1991) found that children smiled more after failure feedback than after success feedback, clearly a problem for the assumption that smiles reflect positive emotional states. In addition, several studies have found that associations between positive emotional states and facial smiles are stronger-and perhaps exclusive to-contexts in which an audience is present (Fernandez-Dols \& Ruiz-Belda, 1995; Fridlund, 1991; Kraut \& Johnston, 1979). Such results comport with Darwin's (1965) analysis of the communicative function of facial behaviour. They also suggest that it may often be hazardous to assume that exhibited facial behaviour provides a "direct readout" of a person's emotional state.

Electromyography (EMG) —Facial behaviours potentially indicative of emotion can also be assessed with facial EMG, which involves measuring electrical potential from facial muscles via the placement of electrodes on the face. The two most frequently targeted muscle groups are the corrugator supercilii (associated with furrowing of the eyebrows) and the zygomatic muscle (associated with raising of the corners of the lips). Results from this literature have converged on the utility of these measures for assessing the valence of a person's emotional state, but are generally viewed as limited in understanding discrete emotional reactions (Cacioppo, Berntson, Klein, \& Poehlmann, 1997; Larsen et al., in press; but see Vrana, 1993). Corrugator muscle activity decreases linearly with the pleasantness of affective stimuli -responding to stimuli across the full valence spectrum, while zygomatic muscle activity increases linearly with the pleasantness of affective stimuli-responding to pleasant stimuli (see Bradley \& Lang, 2000b; Lang et al., 1993; Larsen, Norris, \& Cacioppo, 2003, for reviews). Cacioppo et al. suggested that facial EMG activity reflects implicit evaluation processes (Dimberg, Thunberg, \& Elmehed, 2000), but more work of this type is warranted before coming to firm conclusions (Larsen et al., 2003).

\section{Whole-body behaviour}

Darwin (1965) presented the idea that bodily behaviours are biologically evolved to communicate one's emotional state to conspecifics. Although research on bodily expressions of emotion is relatively sparse (Adolphs, 2002; Van den Stock, Righart, \& de Gelder, 2007), the research that does exist points to the idea that at least certain emotional states may have distinct bodily behaviour signatures. In particular, pride and embarrassment have been linked to expansive and diminutive body postures, respectively. Stepper and Strack (1993) found that participants experienced greater pride if an elevated posture had been implicitly manipulated beforehand. Results from Tracy and Robins' research programme confirm the link between pride and an expansive body posture (Tracy \& Matsumoto, in press; Tracy \& Robins, 2004; Tracy, Robins, \& Lagattuta, 2005). Conversely, Keltner and Buswell (1997) have found that 
embarrassment is reflected in bodily postures associated with minimising one's spatial presence, a result consistent with ethological data on dominance-submission and resulting behavioural postures (Mazur, 2005).

Although embarrassment and pride have been linked to distinct body postures, they have not been linked to distinct facial behaviours (Keltner \& Buswell, 1997; Tracy \& Robins, 2004). App, McIntosh, and Reed (2007) presented a social-functional analysis in which they provided a rationale for why some emotions are primarily associated with facial behaviours, whereas other emotions are primarily associated with whole-body behaviours. They suggested that some emotions, namely anger, fear, disgust, happiness, and sadness, primarily serve individuallevel adaptive functions and should therefore be linked to facial behaviours rather than wholebody behaviours, which are potentially disruptive of an individual's interactions with the environment. On the other hand, the authors suggested that emotions such as embarrassment, guilt, pride, and shame are centrally linked to a person's position within a social status hierarchy. These emotions, then, should be more systematically associated with behaviours that signal to larger groups of individuals one's current emotional state (i.e., whole-body behaviours). Functional analyses of this type appear promising for understanding links between emotions and behaviour, and more research is encouraged.

Summary-The assessment of vocal characteristics appears to be especially useful in understanding levels of emotional arousal, with higher levels of pitch and amplitude associated with higher levels of arousal (Table 1). By contrast, attempts to link emotional valence or discrete emotions to vocal characteristics have been met with mixed success at best, although more sophisticated methods may be capable of doing so in the future. Thus, we conclude that vocal characteristics are primarily reflective of the dimension of emotional arousal.

By contrast, facial behaviours appear to be particularly sensitive to the valence of a person's emotional state (Table 1). An important caveat, though, is that a number of factors such as gender, culture, expressiveness, and the inferred presence of an audience, likely moderate relations between emotional states and facial behaviours. This may be true to such an extent that the absence of changes in facial behaviour should not be equated with the absence of an emotion, and vice versa.

Body posture has not received a great deal of attention as a measure of emotion. Yet, studies that have been conducted suggest that pride and embarrassment are associated with expansive versus diminutive postures, respectively (Table 1). App and colleagues' analysis suggests that such links may be specific to social-status-related emotions (Table 1). If this proves to be the case, body posture measures might be unique among the measures that we reviewed in supporting a discrete emotional perspective.

\section{GENERAL DISCUSSION}

Having reviewed measures of the main components of emotional responding and their sensitivity to different aspects of emotional state, we now comment on two more general questions that cut across our review. The first question is whether dimensional or discrete approaches better capture the structure of emotional responses. The second question is whether multiple measures of emotion converge, as is suggested by the consensual model of Figure 1.

\section{Measures of emotional responding: Dimensional or discrete?}

Emotions have been conceptualised in both dimensional and discrete terms. Dimensional perspectives argue that emotional states are organised by underlying factors such as valence, arousal, and motivational state (Barrett \& Russell, 1999; Watson et al., 1999). Discrete emotion 
perspectives, by contrast, suggest that each emotion (e.g., anger, sadness, happiness) has unique experiential, physiological, and behavioural correlates.

Our review tended to support the dimensional perspective. For example, we reviewed evidence for the idea that emotion specificity has been difficult to establish in the domains of ANS activity, affect-modulated startle responses, and vocal characteristics. Even in relation to measures of emotion that are associated with a greater degree of specificity, such as facial behaviour, dimensional frameworks appear to have substantial explanatory value. Thus, one conclusion of our review is that dimensions appear to capture the lion's share of variance of emotional responses.

Dimensional and discrete perspectives can be reconciled to some extent by conceptualising discrete emotions in terms of combinations of multiple dimensions (e.g., anger = negative valence, high arousal, and high approach motivation) that appear discrete because they are salient (Carver, 2004; Haidt \& Keltner, 1999). If discrete emotions are defined in this manner, there is no necessary antagonism between the two perspectives (Haidt \& Keltner, 1999).

However, to the extent that dimensional perspectives are sufficient for capturing the essence of particular emotional states, such perspectives should be favoured because they are more parsimonious (Watson, 2000). In addition, the available data are incompatible with the notion that discrete emotional states are categorically different from one another, that is, that they are "natural kinds" (cf. Barrett, 2006a).

Of course, some data differentiate emotional states beyond the three factors of valence, arousal, and approach-avoidance (App et al., 2007; Banse \& Scherer, 1996; DeSteno, Petty, Wegener, \& Rucker, 2000; Lerner, Dahl, Hariri, \& Taylor, 2007; Rosenberg \& Ekman, 1994). It may be that investigations using more sophisticated methods (e.g., ANS approaches that take into account combinations of variables or fMRI approaches that examine activity in brain circuits rather than specific brain regions), will support the discrete emotions perspective beyond what has been shown so far.

\section{To what extent do different measures of emotion converge?}

Our review focused on each measure of emotion individually. Thus, an important remaining question is the extent to which different measures of emotion converge in understanding a person's emotional state. The idea that the components of emotion should converge is consistent with theories invoking the idea of "affect programmes". When such programmes are activated, according to these theories, there should be convergent outputs in emotional experience, physiology, and behaviour (see Figure 1 for such a model).

This model has not been well supported in studies that have examined convergence of response systems. Correlations among multiple measures of emotion are moderate at best, small in typical studies, and inconsistent across studies (e.g., Cacioppo et al., 2000; Lang, 1988; Mauss et al., 2004). Psychometric factors could play some role in the lack of convergence typically observed. For example, any one measure of emotion is likely associated with variance unique to it, in turn rendering high levels of convergence difficult to find. Also, most prior studies have assessed coherence in terms of between-individual correlations, thus measuring whether individuals who respond strongly in one component also respond strongly in another. It has been noted that such between-individual analyses might not be the best test of response coherence but that within-individual associations of measures across time more closely denote response-system coherence as implied by the theories of emotion outlined above (Buck, 1980; Lacey, 1967; Stemmler, 1992).

Recent studies have addressed some of these psychometric limitations by using reliable and valid measures and by using within-subject designs (Mauss et al., 2005; Reisenzein, 2000; 
Ruch, 1995). These studies have found higher levels of convergence than prior studies, but the relevant correlations were still low to moderate in strength (e.g., Mauss et al., 2005). In sum, psychometric issues do not appear sufficient in understanding the low levels of convergence observed in studies of this type.

The typical lack of strong convergence among multiple measures of emotion has three important implications. First, it appears that the construct of "emotion" cannot be captured with any one measure considered alone (Lang, 1988; Mandler, 1975; Rachman, 1978). In other words, emotions are multiply determined rather than characterised by a one-dimensional process such as that depicted in Figure 1. Practically speaking, then, the more measures of emotion that are obtained and the better they are tailored to the particular context and research question, the more one will likely learn from a particular study (cf. Larsen \& Prizmic-Larsen, 2006). Second, dissociations among different measures of emotion may be relatively normal rather than necessarily reflective of a dysregulated system. In this context, research that examines the mechanisms that mediate and explain particular response-system dissociations will be particularly useful. Third, there are likely to be moderator variables that affect convergence across measures of emotion (Fridlund, Schwartz, \& Fowler, 1984; Lacey, Bateman, \& Vanlehn, 1953; Picard, Vyzas, \& Healey, 2001). If this is the case, then a more idiographic approach would be necessary to understand the nature of emotional response coherence (Malmo, Shagrass, \& Davis, 1950).

\section{CONCLUSIONS}

The present review examined whether emotional states are associated with specific and invariant patterns of experience, physiology, and behaviour. We suggest that measures of emotional responding appear to be structured along dimensions (e.g., valence, arousal) rather than discrete emotional states (e.g., sadness, fear, anger). Additionally, different measures of emotion appear sensitive to different dimensional aspects of state (e.g., facial EMG is sensitive to valence, whereas skin conductance is sensitive to arousal) and are not strongly related to one another. Practically speaking, then, there is no "gold standard" measure of emotional responding. For theories of emotion, this means that there is no "thing" that defines emotion, but rather that emotions are constituted by multiple, situationally and individually variable processes.

\section{References}

Adolphs R. Recognizing emotion from facial expressions: Psychological and neurological mechanisms. Behavioral and Cognitive Neuroscience Reviews 2002;1(1):21-62. [PubMed: 17715585]

Allen JJB, Urry HL, Hitt SK, Coan JA. The stability of resting frontal electroencephalographic asymmetry in depression. Psychophysiology 2004;41(2):269-280. [PubMed: 15032992]

Anderson AK, Phelps EA. Lesions of the human amygdala impair enhanced perception of emotionally salient events. Nature 2001;411(6835):305-309. [PubMed: 11357132]

Anderson AK, Phelps EA. Is the human amygdala critical for the subjective experience of emotion? Evidence of intact dispositional affect in patients with amygdala lesions. Journal of Cognitive Neuroscience 2002;14(5):709-720. [PubMed: 12167256]

App, B.; McIntosh, D.; Reed, C. A social-functional approach to emotion communication: "How" depends on "why"; Poster presented at the annual meeting of the Society for Personality and Social Psychology; 2007.

Arnold, MB. Emotion and personality. New York: Columbia University Press; 1960.

Bachorowski JA. Vocal expression and perception of emotion. Current Directions in Psychological Science 1999;8(2):53-57.

Bachorowski JA, Owren MJ. Vocal expression of emotion: Acoustic properties of speech are associated with emotional intensity and context. Psychological Science 1995;6(4):219-224. 
Banse R, Scherer KR. Acoustic profiles in vocal emotion expression. Journal of Personality and Social Psychology 1996;70(3):614-636. [PubMed: 8851745]

Bard P. A diencephalic mechanism for the expression of rage with special reference to the sympathetic nervous system. American Journal of Physiology 1928;84:490-515.

Barrett LF. Are emotions natural kinds? Perspectives in Psychological Science 2006a;1:28-58.

Barrett LF. Solving the emotion paradox: Categorization and the experience of emotion. Personality and Social Psychology Review 2006b;10(1):20-46. [PubMed: 16430327]

Barrett LF, Robin L, Pietromonaco PR, Eyssell KM. Are women the "more emotional" sex? Evidence from emotional experiences in social context. Cognition and Emotion 1998;12(4):555-578.

Barrett LF, Russell JA. The structure of current affect: Controversies and emerging consensus. Current Directions in Psychological Science 1999;8(1):10-14.

Barrett LF, Wager TD. The structure of emotion: Evidence from neuroimaging studies. Current Directions in Psychological Science 2006;15(2):79-83.

Berntson, GG.; Cacioppo, JT. From homeostasis to allodynamic regulation. In: Cacioppo, JT.; Tassinary, LG.; Berntson, GG., editors. Handbook of psychophysiology. Vol. 2. New York: Cambridge University Press; 2000. p. 459-481.

Berridge, KC. Pleasure, pain, desire, and dread: Hidden core processes of emotion. In: Kahneman, D.; Diener, E.; Schwarz, N., editors. Well-being: The foundations of hedonic psychology. New York: Russell Sage Foundation; 1999. p. 525-557.

Bonanno GA, Keltner D. The coherence of emotion systems: Comparing “on-line" measures of appraisal and facial expressions, and self-report [Brief Report]. Cognition and Emotion 2004;18(3):431-444.

Bradley MM, Cuthbert BN, Lang PJ. Startle reflex modification: Emotion or attention? Psychophysiology 1990;27(5):513-522. [PubMed: 2274614]

Bradley MM, Cuthbert BN, Lang PJ. Pictures as prepulse: Attention and emotion in startle modification. Psychophysiology 1993;30(5):541-545. [PubMed: 8416082]

Bradley MM, Lang PJ. Affective reactions to acoustic stimuli. Psychophysiology 2000a;37(2):204-215. [PubMed: 10731770]

Bradley, MM.; Lang, PJ. Measuring emotion: Behavior, feeling, and physiology. In: Lane, RD.; Nadel, L., editors. Cognitive neuroscience of emotion. New York: Oxford University Press; 2000b. p. 242-276.

Buck R. Nonverbal behavior and the theory of emotion: The facial feedback hypothesis. Journal of Personality and Social Psychology 1980;38(5):811-824. [PubMed: 7381683]

Buck R. The biological affects: A typology. Psychological Review 1999;106(2):301-336. [PubMed: 10378015]

Cacioppo J, Berntson GG, Klein DJ, Poehlmann KM. The psychophysiology of emotion across the lifespan. Annual Review of Gerontology and Geriatrics 1997;17:27-74.

Cacioppo, JT.; Berntson, GG.; Larsen, JT.; Poehlmann, KM.; Ito, TA. The psychophysiology of emotion. In: Lewis, M.; Haviland-Jones, JM., editors. The handbook of emotion. New York: Guildford Press; 2000.

Cahill L, Haier R, Fallon J, Akire M, Tang C, Keator D, et al. Amygdala activity at encoding correlated with long-term, free recall of emotional information. Proceedings of the National Academy of Sciences 1996;93:8016-8321.

Canli T. Functional brain mapping of extraversion and neuroticism: Learning from individual differences in emotion processing. Journal of Personality 2004;72(6):1105-1132. [PubMed: 15509278]

Cannon WB. Again the James-Lange and the thalamic theories of emotion. Psychological Review 1931;38(4):281-295.

Carver, CS. Self-regulation of action and affect. In: Baumeister, RF.; Vohs, KD., editors. Handbook of self-regulation: Research, theory, and applications. New York: Guilford Press; 2004. p. 13-39.

Christie IC, Friedman BH. Autonomic specificity of discrete emotion and dimensions of affective space: A multivariate approach. International Journal of Psychophysiology 2004;51(2):143-153. [PubMed: 14693364] 
Cohn, JF.; Ekman, P. Measuring facial action. In: Harrigan, JA.; Rosenthal, R.; Scherer, KR., editors. The new handbook of methods in nonverbal behavior research. New York: Oxford University Press; 2005. p. 9-64.

Cook, E., III; Turpin, G. Differentiating orienting, startle, and defense responses: The role of affect and its implications for psychopathology. In: Lang, PJ.; Simons, RF.; Balaban, MT., editors. Attention and orienting: Sensory and motivational processes. Mahwah, NJ: Lawrence Erlbaum Associates, Inc; 1997. p. 137-164.

Cuthbert BN, Bradley MM, Lang PJ. Probing picture perception: Activation and emotion. Psychophysiology 1996;33(2):103-111. [PubMed: 8851238]

Dale AM, Sereno MI. Improved localization of cortical activity by combining EEG and MEG with MRI cortical surface reconstruction: A linear approach. Journal of Cognitive Neuroscience 1993;5(2): $162-176$.

Darwin, C. The expression of the emotions in man and animals. Chicago: The University of Chicago Press; 1965. (Original work published 1872)

Davidson, RJ. Neuropsychological perspectives on affective styles and their cognitive consequences. In: Dalgleish, T.; Power, MJ., editors. Handbook of cognition and emotion. New York: Wiley; 1999. p. 103-123.

Davidson RJ, Ekman P, Saron CD, Senulis JA, Friesen WV. Approach-withdrawal and cerebral asymmetry: Emotional expression and brain physiology I. Journal of Personality and Social Psychology 1990;58(2):330-341. [PubMed: 2319445]

Davis M. Neural systems involved in fear-potentiated startle. Annals of the New York Academy of Sciences 1989;563:165-183. [PubMed: 2570545]

DeSteno D, Petty RE, Wegener DT, Rucker DD. Beyond valence in the perception of likelihood: The role of emotion specificity. Journal of Personality and Social Psychology 2000;78(3):397-416. [PubMed: 10743870]

Detre JA, Floyd TF. Functional MRI and its applications to the clinical neurosciences. Neuroscientist 2000;7:64-79. [PubMed: 11486346]

Dimberg U, Thunberg M, Elmehed K. Unconscious facial reactions to emotional facial expressions. Psychological Science 2000;11(1):86-89. [PubMed: 11228851]

Duffy, E. Activation and behavior. New York: Wiley; 1962.

Ekman P. Facial expressions of emotion: New findings, new questions. Psychological Science 1992;3:3438.

Ekman, P. Basic emotions. In: Dalgleish, T.; Power, MJ., editors. Handbook of cognition and emotion. New York: Wiley; 1999. p. 45-60.

Ekman P, Davidson RJ, Friesen WV. The Duchenne smile: Emotional expression and brain physiology II. Journal of Personality and Social Psychology 1990;58(2):342-353. [PubMed: 2319446]

Ekman P, Friesen WV. Constants across cultures in the face and emotion. Journal of Personality and Social Psychology 1971;17(2):124-129. [PubMed: 5542557]

Ekman, P.; Friesen, WV. Facial action coding system: A technique for the measurement of facial movement. Palo Alto, CA: Consulting Psychologists Press; 1978.

Ekman, P.; Friesen, WV.; Hager, JC. The facial action coding system. Salt Lake City, UT: Research Nexus eBook; 2002.

Ekman P, Levenson RW, Friesen WV. Autonomic nervous system activity distinguishes among emotions. Science 1983;221(4616):1208-1210. [PubMed: 6612338]

Ekman P, Sorenson ER, Friesen WV. Pan-cultural elements in facial displays of emotion. Science 1969;164(3875):86-88. [PubMed: 5773719]

Ellsworth PC. William James and emotion: Is a century of fame worth a century of misunderstanding? Psychological Review 1994;101(2):222-229. [PubMed: 8022957]

Fernandez-Dols, JM.; Ruiz-Belda, MA. Everyday conceptions of emotion: An introduction to the psychology, anthropology and linguistics of emotion. Vol. 81. New York: Kluwer Academic/Plenum Publishers; 1995. Expression of emotion versus expressions of emotions: Everyday conceptions of spontaneous facial behavior. 
Frank MG, Ekman P, Friesen WV. Behavioral markers and recognizability of the smile of enjoyment. Journal of Personality and Social Psychology 1993;64(1):83-93. [PubMed: 8421253]

Frank MJ, O'Reilly RC, Curran T. When memory fails, intuition reigns: Midazolam enhances implicit inference in humans. Psychological Science 2006;17(8):700-707. [PubMed: 16913953]

Fridlund AJ. Sociality of solitary smiling: Potentiation by an implicit audience. Journal of Personality and Social Psychology 1991;60(2):229-240.

Fridlund, AJ.; Ekman, P.; Oster, H. Facial expressions of emotion. In: Siegman, AW.; Feldstein, S., editors. Nonverbal behavior and communication. Vol. 2. Hillsdale, NJ: Lawrence Erlbaum Associates, Inc; 1987. p. 143-223.

Fridlund AJ, Schwartz GE, Fowler SC. Pattern recognition of self-reported emotional state from multiplesite facial EMG activity during affective imagery. Psycho-physiology 1984;21(6):622-637.

Frijda, NH. The emotions. Cambridge, UK: Cambridge University Press; 1986.

Frijda NH. The laws of emotion. American Psychologist 1988;43(5):349-358. [PubMed: 3389582]

Graham, FK. Distinguishing among orienting, defense, and startle reflexes. In: Kimmel, HD.; Olst, EHV.; Orlebeke, JF., editors. The orienting reflex in humans. Hillsdale, NJ: Lawrence Erlbaum Associates, Inc; 1979.

Gross, JJ. Handbook of emotion regulation. New York: Guilford Press; 2007.

Haidt J, Keltner D. Culture and facial expression: Open-ended methods find more expressions and a gradient of recognition. Cognition and Emotion 1999;13(3):225-266.

Harmon-Jones E, Allen JJB. Anger and frontal brain activity: EEG asymmetry consistent with approach motivation despite negative affective valence. Journal of Personality and Social Psychology 1998;74 (5):1310-1316. [PubMed: 9599445]

Harmon-Jones E, Lueck L, Fearn M, Harmon-Jones C. The effect of personal relevance and approachrelated action expectation on relative left frontal cortical activity. Psychological Science 2006;17(5): 434-440. [PubMed: 16683932]

Hawk LW, Cook EW III. Affective modulation of tactile startle. Psychophysiology 1997;34(1):23-31. [PubMed: 9009805]

Heller, W.; Schmidtke, JI.; Nitschke, JB.; Koven, NS.; Miller, GA. States, traits, and symptoms: Investigating the neural correlates of emotion, personality, and psycho-pathology. In: Cervone, D.; Mischel, W., editors. Advances in personality science. New York: Guilford Press; 2002. p. 106-126.

Hess U, Banse R, Kappas A. The intensity of facial expression is determined by underlying affective state and social situation. Journal of Personality and Social Psychology 1995;69(2):280-288.

Holland PC, Gallagher M. Amygdala circuitry in attentional and representational processes. Trends in Cognitive Sciences 1999;3(2):65-73. [PubMed: 10234229]

Izard, CE. The face of emotion. East Norwalk, CT: Appleton-Century-Crofts; 1971.

Izard CE. Levels of emotion and levels of consciousness. Behavioral and Brain Sciences 2007;30(1):9698.

James W. What is an emotion? Mind 1884;9:188-205.

Johnstone, T.; Scherer, KR. Vocal communication of emotion. In: Lewis, M.; Haviland-Jones, JM., editors. Handbook of emotions. New York: Guilford Press; 2000. p. 220-235.

Juslin, PN.; Scherer, KR. Vocal expression of affect. In: Harrigan, JA.; Rosenthal, R.; Scherer, KR., editors. The new handbook of methods in nonverbal behavior research. New York: Oxford University Press; 2005. p. 65-135.

Kagan J. A trio of concerns. Perspectives on Psychological Science 2007;2(4):361-376.

Kappas, A.; Hess, U.; Scherer, KR. Voice and emotion. In: Feldman, RS.; Rime, B., editors. Fundamentals of nonverbal behavior. Cambridge, UK: Cambridge University Press; 1991. p. 200-238.

Keele SW, Ivry R, Mayr U, Hazeltine E, Heuer H. The cognitive and neural architecture of sequence representation. Psychological Review 2003;110(2):316-339. [PubMed: 12747526]

Keltner D, Bonanno GA. A study of laughter and dissociation: Distinct correlates of laughter and smiling during bereavement. Journal of Personality and Social Psychology 1997;73(4):687-702. [PubMed: 9325589]

Keltner D, Buswell BN. Embarrassment: Its distinct form and appeasement functions. Psychological Bulletin 1997;122(3):250-270. [PubMed: 9354148] 
Kiefer SW, Orr MR. Taste avoidance, but not aversion, learning in rats lacking gustatory cortex. Behavioral Neuroscience 1992;106(1):140-146. [PubMed: 1313241]

Koch M, Schnitzler HU. The acoustic startle response in rats-Circuits mediating evocation, inhibition and potentiation. Behavioural Brain Research 1997;89(1-2):35-49. [PubMed: 9475613]

Konorski, J. Integrative activity of the brain. Chicago: University of Chicago Press; 1967.

Kraut RE, Johnston RE. Social and emotional messages of smiling: An ethological approach. Journal of Personality and Social Psychology 1979;37(9):1539-1553.

Kreibig SD, Wilhelm FH, Roth WT, Gross JJ. Cardiovascular, electrodermal, and respiratory response patterns to fear- and sadness-inducing films. Psychophysiology 2007;44(5):787-806. [PubMed: 17598878]

Kring AM, Sloan DM. The facial expression coding system (FACES): Development, validation, and utility. Psychological Assessment 2007;19(2):210-224. [PubMed: 17563202]

Lacey, J. Somatic response patterning and stress: Some revisions of activation theory. In: Appley, MH.; Trumbull, R., editors. Psychological stress: Issues in research. New York: Appleton-Century-Crofts; 1967.

Lacey JI, Bateman DE, Vanlehn R. Autonomic response specificity: An experimental study. Psychosomatic Medicine 1953;15:8-21. [PubMed: 13027503]

Landis, C.; Hunt, W. The startle pattern. Oxford, UK: Farrar \& Rinehart; 1939.

Lane RD, Ahern GL, Schwartz GE, Kaszniak AW. Is alexithymia the emotional equivalent of blindsight? Biological Psychiatry 1997;42(9):834-844. [PubMed: 9347133]

Lang, PJ. What are the data of emotion?. In: Hamilton, V.; Bower, GH.; Frijda, NH., editors. Cognitive perspectives on emotion and motivation. New York: Kluwer Academic/Plenum Publishers; 1988. p. 173-191.

Lang PJ. The varieties of emotional experience: A meditation on James-Lange theory. Psychological Review 1994;101(2):211-221. [PubMed: 8022956]

Lang PJ. The emotion probe: Studies of motivation and attention. American Psychologist 1995;50(5): 372-385. [PubMed: 7762889]

Lang PJ, Bradley MM, Cuthbert BN. Emotion, attention, and the startle reflex. Psychological Review 1990;97(3):377-395. [PubMed: 2200076]

Lang, PJ.; Bradley, MM.; Cuthbert, BN. Motivated attention: Affect, activation, and action. In: Lang, PJ.; Simons, RF.; Balaban, MT., editors. Attention and orienting: Sensory and motivational processes. Mahwah, NJ: Lawrence Erlbaum Associates, Inc; 1997. p. 97-135.

Lang PJ, Greenwald MK, Bradley MM, Hamm AO. Looking at pictures: Affective, facial, visceral, and behavioral reactions. Psychophysiology 1993;30(3):261-273. [PubMed: 8497555]

Larsen, JT.; Berntson, GG.; Poehlmann, KM.; Ito, TA.; Cacioppo, JT. The psychophysiology of emotion. In: Lewis, M.; Haviland-Jones, JM.; Barrett, LF., editors. The handbook of emotions. Vol. 3. New York: Guilford Press; in press

Larsen JT, McGraw AP, Cacioppo JT. Can people feel happy and sad at the same time? Journal of Personality and Social Psychology 2001;81(4):684-696. [PubMed: 11642354]

Larsen JT, Norris CJ, Cacioppo JT. Effects of positive and negative affect on electromyographic activity over zygomaticus major and corrugator supercilii. Psychophysiol-ogy 2003;40(5):776-785.

Larsen, RJ.; Prizmic-Larsen, Z. Measuring emotions: Implications of a multimethod perspective. In: Eid, M.; Diener, E., editors. Handbook of multimethod measurement in psychology. Washington, DC: American Psychological Association; 2006. p. 337-351.

Lazarus, RS. Emotion and adaptation. Oxford, UK: Oxford University Press; 1991.

LeDoux, JE. The emotional brain: The mysterious underpinnings of emotional life. New York: Simon \& Schuster; 1996.

LeDoux JE. Emotion circuits in the brain. Annual Review of Neuroscience 2000;23:155-184.

Leinonen L, Hiltunen T, Linnankoski I, Laakso ML. Expression of emotional-motivational connotations with a one-word utterance. Journal of the Acoustical Society of America 1997;102(3):1853-1863. [PubMed: 9301063]

Lerner JS, Dahl RE, Hariri AR, Taylor SE. Facial expressions of emotion reveal neuroendocrine and cardiovascular stress responses. Biological Psychiatry 2007;61(2):253-260. [PubMed: 17150197] 
Levenson, RW. Blood, sweat, and fears: The autonomic architecture of emotion. In: Ekman, P.; Campos, JJ.; Davidson, RJ.; de Waal, FBM., editors. Emotions inside out: 130 years after Darwin's: The expression of the emotions in man and animals. New York: New York University Press; 2003. p. 348-366.

Libby WL, Lacey BC, Lacey JI. Pupillary and cardiac activity during visual attention. Psychophysiology 1973;10(3):270-294. [PubMed: 4702521]

Mallan KM, Lipp OV. Does emotion modulate the blink reflex in human conditioning? Startle potentiation during pleasant and unpleasant cues in the picture-picture paradigm. Psychophysiology 2007;44(5):737-748. [PubMed: 17532801]

Malmo RB. Activation: A neuropsychological dimension. Psychological Review 1959;66(6):367-386. [PubMed: 14420402]

Malmo RB, Shagrass C, Davis FH. Symptom specificity and bodily reactions during psychiatric interview. Psychosomatic Medicine 1950;12:362-376. [PubMed: 14797915]

Mandler, G. Mind and emotion. New York: Wiley; 1975.

Matthews G, Gilliland K. The personality theories of H. J. Eysenck and J. A. Gray: A comparative review. Personality and Individual Differences 1999;26(4):583-626.

Mauss IB, Levenson RW, McCarter L, Wilhelm FH, Gross JJ. The tie that binds? Coherence among emotion experience, behavior, and physiology. Emotion 2005;5(2):175-190. [PubMed: 15982083]

Mauss IB, Wilhelm FH, Gross JJ. Is there less to social anxiety than meets the eye? Emotion experience, expression, and bodily responding. Cognition and Emotion 2004;18(5):631-662.

Mazur, A. Biosociology of dominance and deference. Lanham, MD: Rowman \& Littlefield; 2005.

Miller MW, Patrick CJ, Levenston GK. Affective imagery and the startle response: Probing mechanisms of modulation during pleasant scenes, personal experiences and discrete negative emotions. Psychophysiology 2002;39(4):519-529. [PubMed: 12212644]

Mitchell TR, Thompson L, Peterson E, Cronk R. Temporal adjustments in the evaluation of events: The "rosy view". Journal of Experimental Social Psychology 1997;33(4):421-448. [PubMed: 9247371]

Murphy FC, Nimmo-Smith I, Lawrence AD. Functional neuroanatomy of emotions: A meta-analysis. Cognitive, Affective \& Behavioral Neuroscience 2003;3(3):207-233.

Murray E. The amygdala, reward and emotion. Trends in Cognitive Sciences 2007;11:489-497. [PubMed: 17988930]

Obrist PA, Webb RA, Sutterer JR, Howard JL. The cardiac-somatic relationship: Some reformulations. Psychophysiology 1970;6(5):569-587. [PubMed: 5485542]

Öhman, A.; Hamm, A.; Hugdahl, K. Cognition and the autonomic nervous system: Orienting, anticipation, and conditioning. In: Cacioppo, JT.; Tassinary, LG.; Berntson, GG., editors. Handbook of psychophysiology. Vol. 2. New York: Cambridge University Press; 2000. p. 533-575.

Panksepp, J. Affective neuroscience: The foundations of human and animal emotions. New York: Oxford University Press; 1998.

Panksepp J. Emotions as viewed by psychoanalysis and neuroscience: An exercise in consilience. NeuroPsychoanalysis 1999;1(1):15-38.

Panksepp J. Neurologizing the psychology of affects: How appraisal-based constructivism and basic emotion theory can coexist. Perspectives on Psychological Science 2007;2(3):281-295.

Patrick CJ. Emotion and psychopathy: Startling new insights. Psychophysiology 1994;31(4):319-330. [PubMed: 10690912]

Paulhus DL, John OP. Egoistic and moralistic biases in self-perception: The interplay of self-deceptive styles with basic traits and motives. Journal of Personality 1998;66(6):1025-1060.

Paulhus DL, Reid DB. Enhancement and denial in socially desirable responding. Journal of Personality and Social Psychology 1991;60(2):307-317.

Pennebaker JW. Physical symptoms associated with blood pressure. Psychophysiology 1982;19(2):201210. [PubMed: 7071299]

Pessoa L, Padmala S, Ungerleider LG. Quantitative prediction of perceptual decisions during nearthreshold fear detection. Proceedings of the National Academy of Sciences of the United States of America 2005;102(15):5612-5617. [PubMed: 15800041] 
Phan KL, Wager TD, Taylor SF, Liberzon I. Functional neuroanatomy of emotion: A meta-analysis of emotion activation studies in PET and fMRI. NeuoroImage 2002;16:331-348.

Picard RW, Vyzas E, Healey J. Toward machine emotional intelligence: Analysis of affective physiological state. IEEE Transactions Pattern Analysis and Machine Intelligence 2001;23(10): 1172-1191.

Pittam J, Gallois C, Callan V. The long-term spectrum and perceived emotion. Speech Communication 1990;9(3):177-187.

Planalp, S. Communicating emotion in everyday life: Cues, channels, and processes. In: Andersen, PA.; Guerrero, LK., editors. Handbook of communication and emotion: Research, theory, applications, and contexts. San Diego, CA: Academic Press; 1998. p. 29-48.

Protopapas A, Lieberman P. Fundamental frequency of phonation and perceived emotional stress. Journal of the Acoustical Society of America 1997;101(4 Pt 1):2267-2277. [PubMed: 9104028]

Rachman S. Human fears: A three systems analysis. Scandinavian Journal of Behaviour Therapy 1978;7 (4):237-245.

Reisenzein R. Exploring the strength of association between the components of emotion syndromes: The case of surprise. Cognition and Emotion 2000;14(1):1-38.

Robinson MD, Clore GL. Episodic and semantic knowledge in emotional self-report: Evidence for two judgment processes. Journal of Personality \& Social Psychology 2002;83(1):198-215. [PubMed: 12088126]

Robinson, MD.; Neighbors, C. Catching the mind in action: Implicit methods in personality research and assessment. In: Eid, M.; Diener, E., editors. Handbook of multimethod measurement in psychology. Washington, DC: American Psychological Association; 2006. p. 115-125.

Robinson, MD.; Sedikides, C. Traits and the self: Toward an integration. In: Corr, PJ.; Matthews, G., editors. Handbook of personality. Cambridge, UK: Cambridge University Press; in press

Rosenberg EL, Ekman P. Coherence between expressive and experiential systems in emotion. Cognition and Emotion 1994;8(3):201-229.

Ruch W. Will the real relationship between facial expression and affective experience please stand up: The case of exhilaration. Cognition and Emotion 1995;9(1):33-58.

Russell JA. A circumplex model of affect. Journal of Personality and Social Psychology 1980;39(6): 1161-1178.

Russell JA. Is there universal recognition of emotion from facial expressions? A review of the crosscultural studies. Psychological Bulletin 1994;115(1):102-141. [PubMed: 8202574]

Russell JA, Barrett LF. Core affect, prototypical emotional episodes, and other things called emotion: Dissecting the elephant. Journal of Personality and Social Psychology 1999;76(5):805-819. [PubMed: 10353204]

Rusting CL. Personality, mood, and cognitive processing of emotional information: Three conceptual frameworks. Psychological Bulletin 1998;124(2):165-196. [PubMed: 9747185]

Sabatinelli D, Bradley MM, Lang PJ. Affective startle modulation in anticipation and perception. Psychophysiology 2001;38(4):719-722. [PubMed: 11446586]

Scherer KR. Emotion as a multicomponent process: A model and some cross-cultural data. Review of Personality \& Social Psychology 1984;5:37-63.

Scherer KR, Bance R, Wallbott HG, Goldbeck T. Vocal cues in emotion encoding and decoding. Motivation and Emotion 1991;15:123-148.

Scherer KR, Wallbott HG. Evidence for universality and cultural variation of differential emotion response patterning. Journal of Personality and Social Psychology 1994;66:310-328. [PubMed: 8195988]

Schneider K, Josephs I. The expressive and communicative functions of preschool children's smiles in an achievement-situation. Journal of Nonverbal Behavior 1991;15(3):185-198.

Schneirla, TC. An evolutionary and developmental theory of biphasic processes underlying approach and withdrawal. In: Jones, MR., editor. Nebraska symposium on motivation, 1959. Lincoln, NE: University of Nebraska Press; 1959. p. 1-42.

Shedler J, Mayman M, Manis M. The illusion of mental health. American Psychologist 1993;48(11): 1117-1131. [PubMed: 8259825] 
Smith CA, Ellsworth PC. Patterns of cognitive appraisal in emotion. Journal of Personality and Social Psychology 1985;48(4):813-838. [PubMed: 3886875]

Stemmler G. The autonomic differentiation of emotions revisited: Convergent and discriminant validation. Psychophysiology 1989;26(6):617-632. [PubMed: 2629011]

Stemmler, G. Differential psychophysiology: Persons in situations. Berlin, Germany: Springer-Verlag; 1992.

Stemmler, G. Physiological processes during emotion. In: Philippot, P.; Feldman, RS., editors. The regulation of emotion. Mahwah, NJ: Lawrence Erlbaum Associates, Inc; 2004. p. 33-70.

Stemmler G, Heldmann M, Pauls CA, Scherer T. Constraints for emotion specificity in fear and anger: The context counts. Psychophysiology 2001;38(2):275-291. [PubMed: 11347873]

Stepper S, Strack F. Proprioceptive determinants of emotional and nonemotional feelings. Journal of Personality and Social Psychology 1993;64:211-220.

Storbeck J, Robinson MD, McCourt ME. Semantic processing precedes affect retrieval: The neurological case for cognitive primacy in visual processing. Review of General Psychology 2006;10(1):41-55.

Sutton SK, Davidson RJ. Prefrontal brain asymmetry: A biological substrate of the behavioral approach and inhibition systems. Psychological Science 1997;8(3):204-210.

Taylor SE, Lerner JS, Sherman DK, Sage RM, McDowell NK. Are self-enhancing cognitions associated with healthy or unhealthy biological profiles? Journal of Personality and Social Psychology 2003;85 (4):605-615. [PubMed: 14561115]

Tellegen A, Watson D, Clark LA. On the dimensional and hierarchical structure of affect. Psychological Science 1999;10(4):297-303.

Tomarken AJ, Davidson RJ, Henriques JB. Resting frontal brain asymmetry predicts affective responses to films. Journal of Personality and Social Psychology 1990;59:791-801. [PubMed: 2254854]

Tompkins, SS. Exploring affect. Cambridge, UK: Cambridge University Press; 1995.

Tracy, JL.; Matsumoto, D. More than a thrill: Cross cultural evidence for spontaneous displays of pride in response to athletic success. Proceedings of the National Academy of Sciences; in press

Tracy JL, Robins RW. Show your pride: Evidence for a discrete emotion expression. Psychological Science 2004;15(3):194-197. [PubMed: 15016291]

Tracy JL, Robins RW, Lagattuta KH. Can children recognize pride? Emotion 2005;5(3):251-257. [PubMed: 16187861]

Van den Stock J, Righart R, de Gelder B. Body expressions influence recognition of emotions in the face and voice. Emotion 2007;7(3):487-494. [PubMed: 17683205]

Volkow ND, Rosen B, Farde L. Imaging the living human brain: Magnetic resonance imaging and positron emission tomography. Proceedings of National Academy of Sciences of the United States of America 1997;94:2787-2788.

Vrana SR. The psychophysiology of disgust: Differentiating negative emotional contexts with facial EMG. Psychophysiology 1993;30(3):279-286. [PubMed: 8497557]

Vrana SR, Spence EL, Lang PJ. The startle probe response: A new measure of emotion? Journal of Abnormal Psychology 1988;97(4):487-491. [PubMed: 3204235]

Wager, TD.; Barrett, LF.; Bliss-Moreau, E.; Lindquist, K.; Duncan, S.; Kober, H., et al. The neuroimaging of emotion. In: Lewis, M.; Haviland-Jones, JM.; Barrett, LF., editors. Handbook of emotions. New York: Guilford Press; 2008. p. 249-271.

Wager TD, Phan KL, Liberzon I, Taylor SF. Valence, gender, and lateralization of functional brain anatomy in emotion: A meta-analysis of findings from neuroimaging. NeuroImage 2003;19:513531. [PubMed: 12880784]

Watson, D. Mood and temperament. New York: Guildford Press; 2000.

Watson D, Wiese D, Vaidya J, Tellegen A. The two general activation systems of affect: Structural findings, evolutionary considerations, and psychobiological evidence. Journal of Personality and Social Psychology 1999;76(5):820-838.

Welte JW, Russell M. Influence of socially desirable responding in a study of stress and substance abuse. Alcoholism: Clinical and Experimental Research 1993;17(4):758-761.

Whalen PJ. Fear, vigilance, and ambiguity: Initial neuroimaging studies of the human amygdala. Current Directions in Psychological Science 1998;7(6):177-188. 


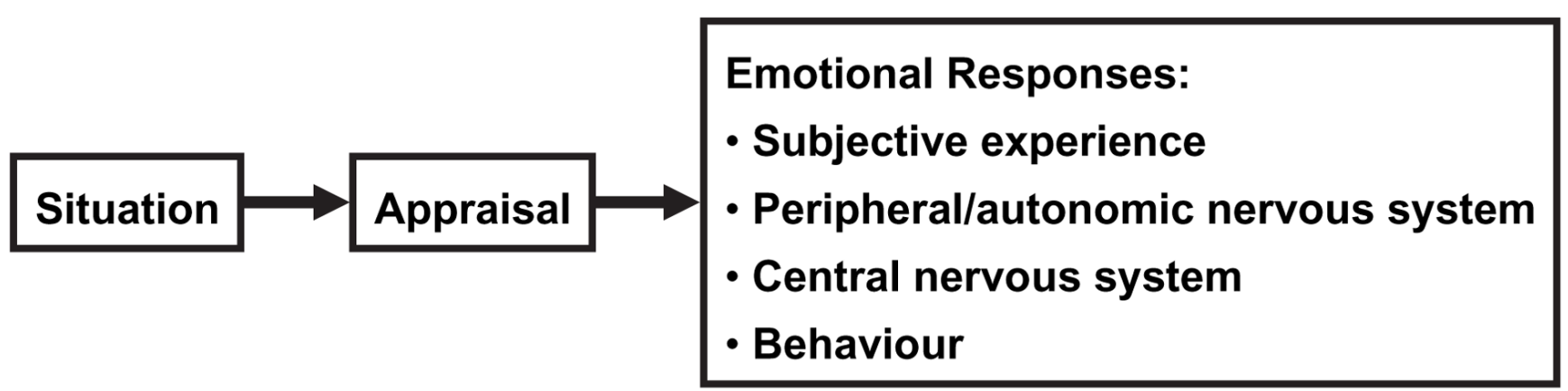

Figure 1.

A consensual component model of emotional responding. 
TABLE 1

Overview of response systems, measures, and emotional states to which they are sensitive

\begin{tabular}{|c|c|c|}
\hline Response system & Measure & Sensitivity \\
\hline Subjective experience & Self-report & Valence and arousal \\
\hline Peripheral physiology (ANS) & Autonomic nervous system (ANS) measures & Valence and arousal \\
\hline Affect-modulated startle & Startle response magnitude & $\begin{array}{l}\text { Valence, particularly at high levels of } \\
\text { arousal }\end{array}$ \\
\hline \multirow[t]{2}{*}{ Central physiology (CNS) } & EEG & Approach and avoidance \\
\hline & fMRI, PET & Approach and avoidance \\
\hline \multirow[t]{4}{*}{ Behaviour } & Vocal characteristics: Amplitude, pitch & Arousal \\
\hline & Facial behaviour: Observer ratings & Valence; some emotion specificity \\
\hline & Facial behaviour: EMG & Valence \\
\hline & Whole body behaviour: Observer ratings & Some emotion specificity \\
\hline
\end{tabular}

